\title{
Uma análise cognitiva do dêitico "aqui" em dados orais e multimodais
}

\author{
A cognitive analysis of the deictic expression «here» in oral and in multimodal data
}

\author{
Hayat Passos Ferraz Pinheiro
}

\author{
Maíra Avelar Miranda
}

Universidade Estadual do Sudoeste da Bahia - UESB - Bahia - Brasil

\begin{abstract}
Resumo: O objetivo da presente pesquisa consiste em verificar os usos prototípicos e não-prototípicos do dêitico aqui em dados orais e multimodais, a partir de registros do corpus C-ORAL-BRASIL e em trechos de vídeos de palestras TEDx (retirados do Youtube). Esta pesquisa dialoga estudos sobre dêixis na perspectiva tradicional (BENVENISTE, 1977, 1988), Construcional (TEIXEIRA; OLIVEIRA, 2012) e com estudos do mesmo fenômeno na perspectiva da Linguística Cognitiva (MARMARIDOU, 2000). Mais especificamente, analisamos, do ponto de vista multimodal, a integração gesto-fala (MCNEILL; CASSELL; LEVY, 1993; AVELAR; FERRARI, 2017). Do ponto de vista teórico, partimos, principalmente, dos conceitos de Metáfora (LAKOFF; JOHNSON, 1980) e Modelos Cognitivos Idealizados (LAKOFF, 1987). A metodologia utilizada na pesquisa consistiu em selecionar duas interações em áudio do corpus C-ORAL-Brasil e três trechos de vídeos de palestras TEDx. Após selecionar as amostras, foram realizadas análises qualitativas. O resultado dessas análises evidenciou que o uso prototípico do dêitico como locativo de espaço ocorre em ambos os contextos (oral e multimodal). Além disso, a ocorrência do "aqui" como marcador também ocorre em ambos os contextos. Porém, no contexto multimodal, esse uso não é acompanhado do gesto prototípico "apontar para baixo", postulado em outros estudos (AVELAR; FERRARI, 2017). Observamos, também, que a ocorrência metafórica do dêitico, mais especificamente das metáforas "TEMPO É ESPAÇO" e "IDEIAS SÃO OBJETOS", ocorre apenas no contexto multimodal.
\end{abstract}

Palavras-chave: Dêixis. Oralidade; Multimodalidade. Aqui.

Abstract: The aim of this research is to verify the prototypical and non-prototypical uses of the deictic "here" in oral and in multimodal data, using C-ORAL-BRASIL and TEDx talking snippets (from YouTube). This research dialogs with studies on deixis in a traditional perspective (BENVENISTE, 1977, 1988), Construcional (TEIXEIRA; OLIVEIRA, 2012) and with studies of the same phenomena in a Cognitive Linguistics perspective (MARMARIDOU, 2000). More specifically, we analyze, from a multimodal point of view, the gesture-speech integration (MCNEILL; CASSELL; LEVY, 1993); (AVELAR e FERRARI, 2017). From a theoretical point of view, we start with the concepts of Metaphor (LAKOFF ; JOHNSON, 1980) and Idealized Cognitive Models (LAKOFF, 1987). The methodology that was used in this research consisted in selecting two audio samples from C-ORAL-Brasil and three video samples from TEDx talking's. After select the samples, qualitative analyses were carried out. The result of these analyses revealed that the prototypical use of the deictic as space locative occurs in both contexts (oral and multimodal). Additionally, the occurrence of "here" as a discursive marker also occurs in both contexts. Nevertheless, in the multimodal context, this use is not accompanied by the prototypical gestures "point down", proposed by other studies. We also observe that the metaphorical occurrence of the deictic, more specifically of the metaphor "TIME IS SPACE" and "IDEAS ARE OBJECTS", occurs only in the multimodal context.

Key-words: Deixis. Orality. Multimodality. Here. 


\section{Introdução}

A concepção tradicional de dêixis foi estabelecida por Benveniste $(1976,1988)$. O termo "dêixis", em grego, significa "ação de mostrar, indicar, assinalar" e é reservado aos pronomes de valor demonstrativo e circunstancial, que mensuram a proximidade/distância no tempo e espaço a partir da instância discursiva que contém /eu/. Na concepção do autor, os dêiticos representados pelos pronomes demonstrativos são também indicadores de ostensão, ou seja, fixam fronteiras espaciais e temporais de acordo com a posição do eu no ato comunicativo. Dessa forma, para Benveniste, o que define a dêixis é a relação do indicador (que seja de pessoa, tempo ou lugar) e a presente instância do discurso.

Além da concepção tradicional, esta pesquisa dialoga com estudos sobre a dêixis em uma perspectiva construcional (TEIXEIRA; OLIVEIRA, 2012) e com estudos do mesmo fenômeno na perspectiva da Linguística Cognitiva (MARMARIDOU, 2000). Marmaridou (2000) defende que o Modelo Cognitivo Idealizado (doravante $\mathrm{MCl}$ ) da dêixis envolve $\mathrm{o}$ ato de apontar para uma entidade no espaço, além de ser realizado por um falante autorizado e direcionado para um interlocutor não focalizado. Dessa forma, uma expressão dêitica é aquela que constrói um espaço mental no qual o falante e o destinatário são coapresentados em determinado ponto no tempo.

Guiados por essa perspectiva cognitiva, a partir, sobretudo, dos conceitos teóricos de Metáfora Conceptual (LAKOFF; JOHNSON, 1980) e Modelos Cognitivos Idealizados (LAKOFF, 1987), verificamos os usos prototípicos e não-prototípicos do dêitico "aqui" em dados orais e multimodais. Com relação às análises do dêitico "aqui" em contexto multimodal, consideramos a integração entre gestos e fala (MCNEILL; CASSELL; LEVY, 1993, AVELAR; FERRARI, 2017).

Para a realização das análises, selecionamos duas ocorrências do dêitico "aqui" em dados orais, uma prototípica e outra não prototípica. As amostras selecionadas pertencem a interações gravadas em áudio, presentes no corpus C-ORAL-Brasil I (RASO; MELLO, 2012). Para a realização da análise multimodal, selecionamos três ocorrências do dêitico "aqui": uma prototípica e duas não prototípicas, que foram retiradas de trechos da palestra TEDx "Felicidade é aqui e agora". Categorizamos o uso prototípico do dêitico "aqui" como locativo. Já os usos não prototípicos foram analisados como estruturados metaforicamente ou como marcadores discursivos. Detalharemos as fontes de coleta dos dados, bem como os diferentes usos do dêitico "aqui" na seção referente à análise de dados.

$\mathrm{Na}$ presente pesquisa, optamos por iniciar os estudos pela relação entre dêixis e cognição, explorando as noções de Esquemas Imagéticos (JOHNSON, 1987; LAKOFF, 1987) e as definições de dêixis e dêixis metafórica em uma perspectiva cognitiva (MARMARIDOU, 2000). Em um segundo momento, discutimos a relação entre dêixis e gestos. Posteriormente, apresentamos a metodologia utilizada na pesquisa e a análise de dados. E, por fim, exploramos os resultados e a discussão, seguidos pelas considerações finais.

\section{$20 \mathrm{MCl}$ da dêixis}

O $\mathrm{MCl}$ da dêixis proposto por Marmaridou (2000) possui uma estrutura imago-esquemática de CENTRO-PERIFERIA. Para discorrer sobre essa estrutura, retomaremos as considerações feitas por Lakoff (1987) e Johnson (1987) a respeito desse Esquema Imagético (doravante, El).

Ao definir o El centro-periferia, Lakoff (1987) estabelece que esse esquema está baseado na nossa experiência corporal. Segundo ele: "nós experienciamos nossos corpos como tendo centros (o tronco e os órgãos internos) e periferias (dedos da mão, dedos do pé, cabelos)" (LAKOFF, 1987, p.274). Além disso, para o autor, os centros são vistos como mais importantes do que as periferias de duas maneiras: primeiramente, lesões das partes centrais são mais sérias do que as lesões das partes periféricas. De forma similar, o centro define a identidade de um indivíduo e as periferias, não. Lakoff 
(1987) exemplifica que, se uma pessoa cortar o cabelo ou perder ou dedos (periferias), continuará sendo a mesma pessoa. Portanto, afirma o autor, "a periferia é vista como parte dependente do centro, mas não o contrário (...) (má circulação poderá afetar a saúde do cabelo, mas perder o cabelo não afetará o sistema circulatório)" (LAKOFF, 1987, p.274). Antes de encerrar as considerações sobre o El centroperiferia, Lakoff (1987) define os elementos estruturantes desse esquema, são eles: uma entidade, um centro e uma periferia.

Já Johnson (1987), ao discorrer sobre o El centro-periferia, também assume a base experiencial e corporal desse esquema. Assim, afirma que: "nosso mundo irradia a partir de nossos corpos como centros perceptuais, a partir dos quais nós vemos, ouvimos, tocamos, experimentamos e cheiramos nosso mundo" (JOHNSON, 1987, p.124). Para ele, nosso espaço perceptual define um domínio de objetos macroscópicos que se encontram a distâncias variáveis de nós. Dessa forma, nós podemos focalizar nossa atenção em um objeto ou campo perceptual depois do outro. Então, o que se configura como "figura" em um momento, pode tornar-se "fundo" em outro.

Johnson (1987, p.124) assevera que "de certa distância, a partir do centro perceptual, nosso mundo 'desaparece' em um horizonte perceptual e já não nos apresenta os objetos discretos". Dessa maneira, de acordo com o autor, podemos nos mover em uma direção do horizonte e, consequentemente, abrir um novo território perceptual, mas isso irá desestabilizar nossos horizontes fora do nosso alcance. Johnson (1987) afirma que as considerações feitas anteriormente descrevem o contorno do El centroperiferia, representado graficamente na figura a seguir:

\section{Figura 01 Center-Periphery}

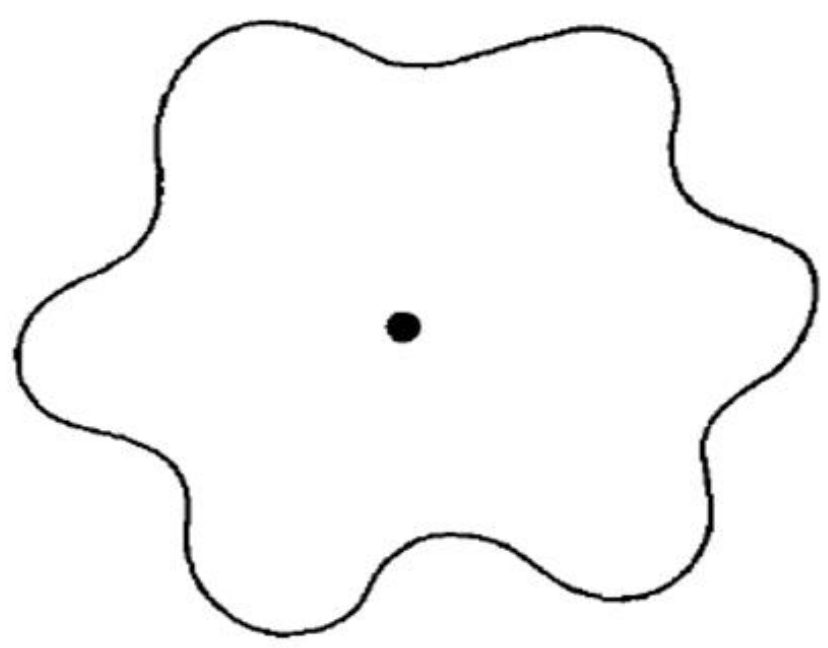

Fonte: JOHNSON, 1987, p.124

Segundo o autor, o ponto central da figura representa nosso centro perceptual e experiencial, que define nosso espaço experiencial e desaparece em nosso horizonte (linha ondulada). Além de discutir o esquema centro-periferia em temos de espaço perceptual, Johnson (1987) aponta que o El possui uma estrutura recorrente no nosso espaço experiencial, pois no nosso mundo "algumas coisas, eventos e pessoas são mais importantes que outras elas emergem em nossa experiência e são mais centrais para as nossas interações, outras são relativamente periféricas em dado ponto no tempo" (JOHNSON, 1987, p.124).

Entendido dessa forma, explicitada por Johnson, o El centro-periferia possui uma interpretação mais abstrata, pois, segundo o autor, demonstra, além de uma estrutura do nosso campo perceptual, uma importância na estruturação do nosso mundo social, econômico, político, religioso, filosófico. Para o autor, esses "objetos" que se configuram significantes no nosso campo experiencial são tanto entidades abstratas como entidades concretas, por meio das quais nosso interesse é delimitado.

Aplicando a estrutura imago-esquemática centro-periferia para o $\mathrm{MCl}$ da dêixis, abordaremos as considerações feitas por Marmaridou (2000). A autora afirma que o $\mathrm{MCl}$ da dêixis envolve $\mathrm{o}$ ato de apontar para uma entidade no espaço, além de ser realizado 
por um falante autorizado e direcionado para um interlocutor não focalizado. Dessa forma, uma expressão dêitica, para a autora, é aquela que constrói um espaço mental no qual o falante e o destinatário são coapresentados em determinado ponto no tempo. Em suma, o espaço mental evocado por uma expressão dêitica envolve a conceptualização de um centro dêitico. Fica claro que a Gestalt cognitiva da dêixis está baseada numa representação linguística, pois trata-se de: "uma representação simbólica, um ato físico que é realizado por um ser humano na presença de outro ser humano" . (MARMARIDOU, 2000, p.100).

De acordo com Marmaridou (2000), a representação primitiva da intenção humana está provavelmente no centro do fenômeno dêitico. Tomando o ato físico como fonte do ato linguístico, prontamente considera-se a definição do falante como centro dêitico. Este é o centro no qual o ato é iniciado, concebivelmente pela extensão de um braço em relação à entidade no espaço. Dessa forma, o centro é, obviamente, o falante, enquanto a preferia carrega o objeto dêitico como uma entidade no espaço. A autora também reitera que elementos da periferia dependem do centro (o falante). Significativamente, quando o falante aponta para ele mesmo como uma entidade no espaço, a distância entre o centro e periferia é neutralizada. Por fim, é importante perceber que, nesse ponto, o falante também é conceptualizado como uma entidade no espaço. É isso que faz com que o "apontar para si"; a "auto-referência" (self-pointing/ self-reference) seja possível.

Além de ser concebido em um domínio experiencial, em relação aos domínios do espaço físico, o $\mathrm{MCl}$ da dêixis também pode ser estruturado metaforicamente. Nesse sentido, Marmaridou (2000) afirma que "talvez a contribuição mais significativa da metáfora com relação à estrutura da dêixis seja o entendimento dos parâmetros sociais do evento de fala em termos de espaço físico para estabelecer o que pode ser chamado de espaço social para os objetivos da análise proposta" (MARMARIDOU, 2000, p.101).
Ainda se referindo à metáfora, a autora retoma as definições de metáfora conceptual (LAKOFF; JOHNSON, 1980). De acordo com essa definição: uma metáfora conceptual envolve dois domínios experienciais nos quais um é entendido em termos de outro. Normalmente, um domínio abstrato (o alvo) e um domínio concreto (a fonte) (LAKOFF; JOHNSON, 1980). Seguindo o que propõem Lakoff e Johnson, a autora aponta que o domínio experiencial do espaço físico é mapeado em um domínio abstrato de uma realidade social e se estrutura de uma maneira consistente com o nosso entendimento da realidade.

Um exemplo de domínio abstrato é o tempo, que, de acordo com Marmaridou (2000), pode ser entendido em termos de referência espacial. Para a autora, essa relação entre domínios espaciais e temporais vem sendo atestada em trabalhos importantíssimos da área de Linguística Cognitiva, tendo sido inicialmente observada por Lakoff e Johnson (1980). A autora retoma a metáfora "TEMPO É UM OBJETO MÓVEL" e explica que, por causa dessa metáfora, o tempo também tem recebido uma orientação frente-trás com relação à direção do movimento. Nesses termos, o futuro está virado em nossa direção enquanto ele se move para nos encontrar. Isso pode ser demonstrado em expressões como "eu não posso encarar o futuro". Intrigantemente, para o propósito da análise do $\mathrm{MCl}$ da dêixis, quando o tempo é construído como um objeto em movimento, ele também está em direção ou longe do falante. No exemplo "o tempo virá" (the time will come) o objeto está se movendo com o falante como alvo ou destino. Este está se movendo adiante de uma linha ou caminho em direção ao centro dêitico. Concebivelmente, Marmaridou (2000) afirma que:

quando o objeto em movimento alcança o alvo, o tempo será 'agora', tempo central ou, em uma classificação tradicional, tempo de codificação. De maneira similar, em "o tempo já passou há muito tempo quando..." o objeto está se movendo para longe do falante, em direção ao passado. Nesse caso o falante é o ponto inicial de movimento. O tempo está se distanciando do centro dêitico, longe do agora, no interior do passado (MARMARIDOU, 2000, p.102). 
Com relação ao entendimento metafórico do tempo em termos de referência espacial, evidências também têm sido coletadas por meio do estudo dos gestos no âmbito da Linguística Cognitiva, conforme demonstraremos na seção seguinte.

\subsection{Dêixis e gestos}

Para tratarmos da dêixis em compostos verbogestuais, retomaremos algumas considerações feitas em um estudo realizado por Calbris (2008). A autora propõe que o eixo de progressão frente-trás é projetado para o eixo transversal. Este último se refere não apenas em relação à simetria (esquerda/direita), mas também se caracteriza como eixo de progressão simétrica, indo da esquerda para a direita, em conformidade com a direção da escrita no mundo ocidental. Esse eixo transversal representa, metaforicamente, a progressão dos eventos observados; representa uma sucessão lógico-temporal. A autora cita um exemplo que apresenta três esquemas perceptuais: primeiramente, o eixo da simetria (dois elementos sistematicamente situados), em segundo lugar, o eixo direcional do caminhar (progressão espaço-temporal pessoal de trás para frente), e, por último, o eixo direcional da escrita ocidental (progressão dos eventos da esquerda para direita). A autora assevera que a dêixis abstrata, metafórica, emerge da experiência sensóriomotora do corpo, sendo motivada fisicamente.

$\mathrm{Na}$ análise de contextos multimodais, conforme afirmam Avelar e Ferrari (2017), as expressões dêiticas são frequentemente associadas ao gesto de apontar. De acordo com as autoras, os gestos de apontar "são as 'ações não linguísticas' responsáveis pelo estabelecimento da inter-relação referencial entre o enunciado e as circunstâncias espaçotemporais de sua ocorrência" (AVELAR; FERRARI, 2017, p.75). Para Kendon (2004 apud AVELAR; FERRARI, 2017) os gestos de apontar possuem um padrão comum de movimento e, também, uma trajetória em linha reta e bem definida. Esses gestos são realizados em uma direção específica, direcionados a um alvo específico. Eles podem se referir "tanto ao espaço imediato partilhado pelos interlocutores e, consequentemente, ao objeto concreto no ambiente, como também à estruturação de ideias do falante". (AVELAR; FERRARI, 2017, p.75).

Portanto, haveria uma utilização dêitica referente à localização no espaço e outra referente à utilização abstrata - metafórica (MCNEILL; CASSELL; LEVY, 1993). No que se refere à dêixis metafórica, esta poderia ser instanciada pelas metáforas "TEMPO É ESPAÇO" (LAKOFF; JOHNSON, 1980) e "IDEIAS SÃO OBJETOS" (MCNEILL; CASSELL; LEVY, 1993). Essas metáforas serão mais amplamente exploradas na seção que concerne à análise do dêitico "aqui" no corpus multimodal. No que concerne, especificamente, ao dêitico "aqui", a representação gestual prototípica desse dêitico seria representada pelo gesto de "apontar para baixo" (AVELAR; FERRARI, 2017). Verificaremos se, do ponto de vista gestual, essa ocorrência será encontrada, tanto no contexto concreto, quanto no contexto abstrato.

\subsection{A dêixis na perspectiva construcional: breves considerações}

Além de analisarmos as ocorrências metafóricas do dêitico "aqui" nos corpora, examinaremos amostras em que o dêitico ocorre como marcador discursivo. Para isso, seguiremos as proposições de Teixeira e Oliveira (2012). As autoras apresentam uma tipologia funcional dos marcadores discursivos formados a partir do esquema construcional verbo locativo, como podemos ilustrar no quadro a seguir:

Quadro 1 - Distribuição das expressões de acordo
com a semântica verbal em níveis de
esquematicidade




\begin{tabular}{|c|c|c|c|c|c|c|}
\hline $\begin{array}{c}\text { Nivel de } \\
\text { esquematicidade }\end{array}$ & \multicolumn{6}{|c|}{ Tipo de construção } \\
\hline MACRO & \multicolumn{6}{|c|}{ VerboLocativo marcador discursivo - VLOCMD } \\
\hline $\mathrm{MESO}^{1}$ & VcogLoc & VelocLoc & VintLoc & VmovLoc & VpereLoe & $\begin{array}{l}\text { VprocLo } \\
\text { c }\end{array}$ \\
\hline MICRO & $\begin{array}{l}\text { quero lá, } \\
\text { sei lá, } \\
\text { sabe lá }\end{array}$ & $\begin{array}{l}\operatorname{dig}(a) \\
\text { ai, diga } \\
\text { lá, } \\
\text { fal(a) ai }\end{array}$ & $\begin{array}{l}\text { (es)t(á) ai, } \\
\text { (es)tamo(s } \\
\text { ) aí, fic(a), } \\
\text { ai }\end{array}$ & $\begin{array}{l}\text { cheg(a) aí, } \\
\text { chega[r] lá, } \\
\text { vá lá, vamos } \\
\text { lá, vem cá }\end{array}$ & $\begin{array}{l}\text { escuta } \\
\text { aqui, } \\
\text { olh(a) ai, } \\
\text { olh(a) } \\
\text { aqui, olha } \\
\text { lá, vê lá }\end{array}$ & $\begin{array}{l}\text { (es)per(a } \\
\text { ) ai, } \\
\text { espera lá, } \\
\text { segur(a) } \\
\text { ai }\end{array}$ \\
\hline CONSTRUCTO & $\begin{array}{l}\text { quero lá, } \\
\text { sei lá. } \\
\text { sabe lá }\end{array}$ & $\begin{array}{l}\text { diga ai, } \\
\text { diga lá, } \\
\text { fala ai }\end{array}$ & $\begin{array}{l}\text { está ai, } \\
\text { estamos } \\
\text { ai, fica ai }\end{array}$ & $\begin{array}{l}\text { chega aí, } \\
\text { chega[r] lá, } \\
\text { vá lá, vamos } \\
\text { lá, vem cá }\end{array}$ & $\begin{array}{l}\text { escuta } \\
\text { aqui, olha } \\
\text { ai, olha } \\
\text { aqui, olha } \\
\text { lá, vê lá }\end{array}$ & $\begin{array}{l}\text { espera aí, } \\
\text { espera lá, } \\
\text { segura ai }\end{array}$ \\
\hline
\end{tabular}

Fonte: TEIXEIRA; OLIVEIRA, 2012, p.21

De acordo com esse esquema, analisaremos ocorrências como a do marcador discursivo "escuta aqui". Nesse caso, consideramos, assim como afirmam Teixeira e Oliveira (2012), que o aqui, como marcador discursivo, migrou de usos mais prototípicos, dêiticos locativos, para usos menos prototípicos, deslocando o foco de atenção do interlocutor do espaço para o texto. Detalharemos a análise das ocorrências encontradas nos corpora mais a frente, na seção referente à análise de dados.

\section{Metodologia}

Tendo em vista que o objetivo da pesquisa consiste em verificar os usos prototípicos e nãoprototípicos do dêitico "aqui" em dados orais e multimodais, selecionamos duas interações em áudio do corpus C-ORAL-Brasil I e três trechos do vídeo da palestra motivacional "Felicidade é aqui e agora".

\subsection{Dados orais}

As duas ocorrências do dêitico "aqui" em dados orais, uma prototípica e outra não prototípica, foram retiradas de uma interação em áudio presente no corpus C-ORAL-Brasil I (RASO; MELLO, 2012). O corpus C-ORAL-Brasil I é constituído por dados de fala espontânea do Português Brasileiro, representativo do dialeto mineiro, sobretudo da região metropolitana da cidade de Belo Horizonte, Minas
Gerais. Os procedimentos de coleta foram baseados no C-ORAL-ROM para corpora de espanhol, francês, italiano e português europeu (CRESTI; MONEGLIA, 2005), seguindo a arquitetura e amostragem desses corpora. Portanto, o C-ORAL-BRASIL I se configura como um corpus de terceira geração, com o texto e o áudio alinhados. A interação de áudio, com transcrição alinhada, da qual coletamos as duas amostras, faz parte da seguinte classificação no corpus: de diálogo, informal, público. Os participantes do diálogo são um vendedor de sapatos e a sua cliente. O diálogo acontece em uma loja de sapatos em Belo Horizonte, e seu tópico é a escolha de sandálias para comprar.

\subsection{Dados multimodais}

As três ocorrências do dêitico "aqui" em dados multimodais, uma prototípica e duas não prototípicas, foram retiradas de trechos da palestra TEDx "Felicidade é aqui e agora". As palestras TEDx fazem parte de um programa de eventos, organizado de forma independente, que reúne diferentes pessoas que compartilham suas opiniões sobre diversos assuntos (seguindo o modelo das conferências TED). As palestras, realizadas nesses eventos, são transformadas em vídeos TEDx Talks. A palestra TEDx que utilizamos foi proferida em um TEDx São Paulo pelo Professor Clóvis Barros Filho. Trata-se de uma palestra motivacional, cujo principal tópico de 
discussão consiste na definição de felicidade, de acordo com proposições filosóficas, e na necessidade de viver e ser feliz no momento presente.

Para analisar os dados multimodais, mais especificamente, a integração gesto-fala (MCNEILL; CASSELL; LEVY, 1993; AVELAR; FERRARI, 2017), foi preciso isolar os golpes (strokes) gestuais, pois como aponta Cienki (2007, p. 425), gestos constituem "movimentos distintos de esforço identificável das mãos e antebraços, ou seja, o golpe (stroke) dos gestos". Dessa forma, fotografamos os golpes gestuais nas três ocorrências do dêitico "aqui", uma vez que as três ocorrências verbais selecionadas ocorreram acompanhadas de gesto.

\section{Análise dos dados}

Os trechos que selecionamos para análise das ocorrências prototípicas e não-prototípicas do aqui nos corpora serão explorados nesta seção. Primeiramente, discutiremos as ocorrências nos dados orais e, posteriormente, nos dados multimodais.

\subsection{Dados orais}

Nos dados orais, encontramos uma ocorrência prototípica do dêitico "aqui" e outra não prototípica. Essas ocorrências foram selecionadas em duas interações de áudio. A primeira interação de áudio que selecionamos está descrita a seguir:

*EUG: [153] ela era oitenta-e-nove //\$

*EUG: [154] era [/1] era a rasteira mais cara que tinha aqui (grifo nosso)//\$

(EUG: [155] pôs na liqüidação por cinqüenta-e-nove / quando tava na liquidação

No trecho em análise, o vendedor (EUG) explica sobre o preço de determinada sandália. Ao analisar a ocorrência do dêitico "aqui" nesse trecho, consideramos que seu uso ocorreu de forma prototípica, uma vez que o "aqui" é utilizado como locativo ("aqui na loja"), portanto se refere à instância espacial. Já a segunda interação de áudio está descrita a seguir:

*EUG: [77] enquanto <cê> \&dis [/1] experimenta essa aí / eu vou pegar as outras aqui (grifo nosso) //\$

*JAN: [78] <tá> //\$

*EUG: [79] dá licença //\$

*JAN: [80] Nossa / essa é ótima //\$

*EUG: [81] olha / eu peguei as três caixas que eu achei trinta-e-nove lá / mas / todas três são desse modelo de cruzar $/ / \$$

*JAN: [82] uhn //\$

Nesse trecho, o vendedor (EUG) conversa com a cliente (JAN) sobre as sandálias que ela está experimentando. Ao analisar a ocorrência do dêitico "aqui" nesse trecho, consideramos que o dêitico possuiu um uso não-prototípico, funcionando como marcador discursivo, mais especificamente, como marcador de ênfase. Nesse sentido, a omissão do dêitico seria perfeitamente possível ("enquanto cê experimenta, eu vou pegar as outras"), uma vez que ele exerce uma função paradiscursiva, interferindo mais sobre o "como" é dito, do que sobre "o que" é dito.

\subsection{Dados multimodais}

Nos dados multimodais, encontramos três ocorrências do dêitico "aqui": uma prototípica e duas não prototípicas. Na primeira amostra de vídeo, na qual capturamos os golpes gestuais, encontramos, primeiramente, a ocorrência prototípica do "aqui":

Ocorrência prototípica do dêitico "aqui" 


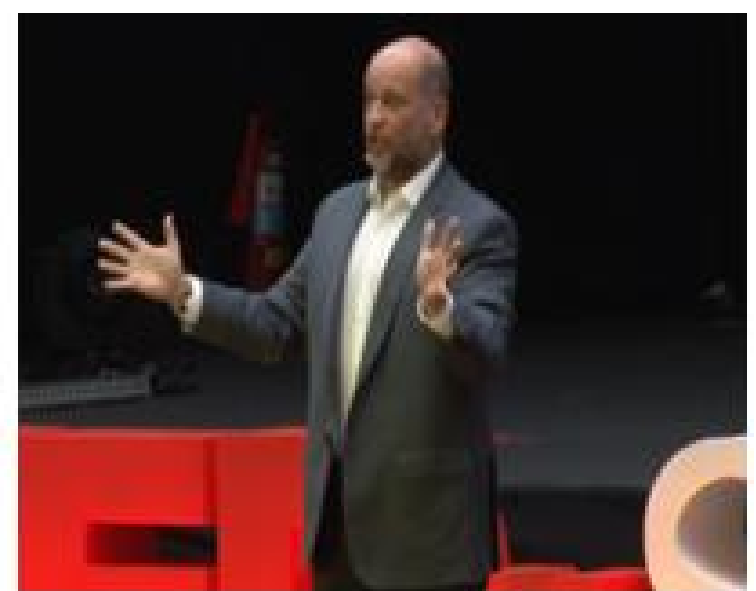

"Aqui (1)

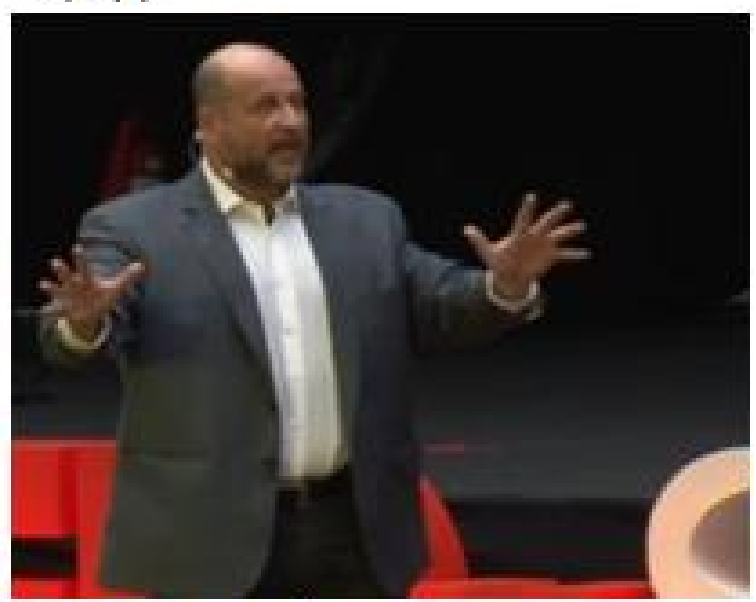

nesse canto do estádio (2)

Nesta amostra, é possível observar o uso do dêitico como locativo (espacial). Trata-se, portanto, de uma ocorrência prototípica. A análise do gesto permite corroborar essa conclusão, pois as mãos espalmadas que se abrem na diagonal, para fora do corpo, instanciando 0 Esquema Imagético SUPERFÍCIE .

$\mathrm{Na}$ segunda amostra analisada, há um uso não-prototípico do "aqui":

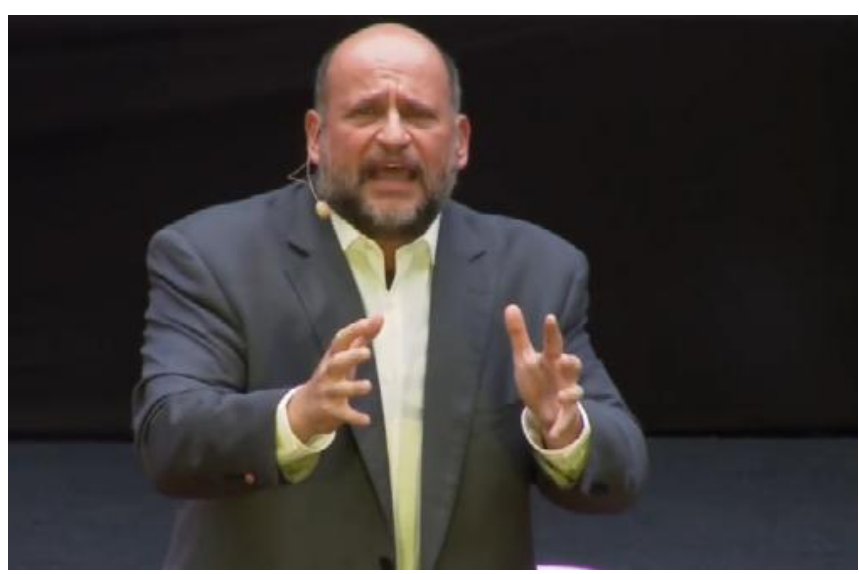

(1) "Escuta aqui"
$\mathrm{Na}$ amostra em questão, a expressão "escuta aqui”, conforme propõem Teixeira e Oliveira (2012), faz parte do esquema construcional verbo locativo e pode ser concebida como uma microconstrução. Ao analisarmos o gesto que co-ocorre com essa microconstrução, em que as palmas das mãos encontram-se voltadas uma para a outra, "como se" (CIENKI, 2005) o falante estivesse segurando algo (em 3D), evidenciamos a ocorrência do EI OBJETO, que instancia a metáfora "IDEIAS SÃO OBJETOS" (MCNELL; CASELL; LEVY, 1993). Além disso, assumimos, em consonância com as proposições de Teixeira e Oliveira (2012), que "a combinação da forma verbal escuta com o locativo aqui traz para este marcador nuance de sentido. O sentido de escutar como 'prestar atenção para ouvir', aliado ao de aqui, que indica proximidade e pontualidade, permite um leitura mais intimista" (TEIXEIRA; OLIVEIRA, 2012, p.37, grifos das autoras). Por fim, na terceira amostra de vídeo, encontramos outra ocorrência, nãoprototípica, do dêitico "aqui":

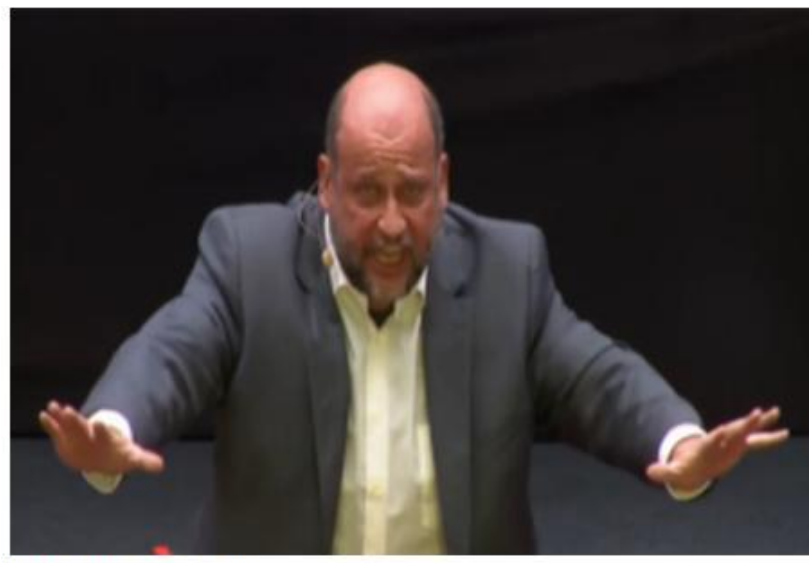

"Admita, neste segundo: aqui (1)

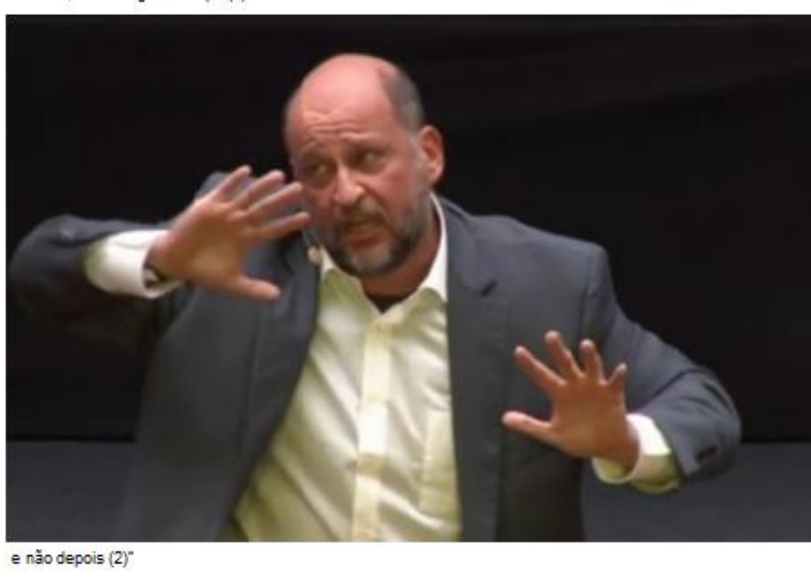

Ao analisarmos o nível verbal da ocorrência em questão, verificamos a emergência da Metáfora 
Conceptual "TEMPO É ESPAÇO" (LAKOFF; JOHNSON, 1980), uma vez que o "aqui" co-ocorre com expressões espaciais ("neste segundo" e "depois"). Do ponto de vista gestual, a marcação de uma posição espacial central, ao se enunciar o "aqui", seguida da representação icônica de "empurrar para a direita" ao se enunciar "e não depois", instancia o EI "TRAJETÓRIA", desdobrado na Metáfora Conceptual "TEMPO É UM OBJETO MÓVEL" (já abordada na seção 1). Essa análise ratifica os postulados de Calbris (2008) de que o eixo da esquerda para a direita, na cultura ocidental, marca, no espaço, o tempo passado (para a esquerda), presente (no centro) e futuro (para a direita).

\subsection{Síntese dos resultados}

Os resultados das análises qualitativas evidenciaram que, nas ocorrências analisadas, o uso prototípico do dêitico como locativo de espaço ocorre em ambos os contextos (oral e multimodal). No contexto multimodal, a marcação espacial também ocorre por meios dos gestos, que instanciam o El SUPERFÍCIE. Além disso, a ocorrência do "aqui" como marcador também ocorre em ambos os contextos. Porém, no contexto multimodal, esse uso não é acompanhado do gesto prototípico "apontar para baixo", postulado em outros estudos (AVELAR; FERRARI, 2017), pois esse gesto ocorreria no contexto prototípico. Ao invés disso, é como se as mãos estivessem segurando um (EI) OBJETO. Nesse sentido, o gesto instancia a Metáfora Conceptual "IDEIAS SÃO OBJETOS" (MCNEILL; CASSELL; LEVY, 1993), que ocorre apenas no contexto multimodal. Observamos também, apenas no contexto multimodal, outra ocorrência metafórica do "aqui", mais especificamente da Metáfora Conceptual "TEMPO É ESPAÇO” (LAKOFF; JOHNSON, 1980), que ocorre no nível verbal. No nível gestual, é instanciado o EI "TRAJETÓRIA", desdobrado na metáfora gestual "TEMPO É UM OBJETO MÓVEL", construída no eixo espacial "para trás (passado), no meio (presente) e para frente (futuro)" (CALBRIS, 2008).

\section{Considerações finais}

Com o objetivo de verificar os usos prototípicos e não-prototípicos do dêitico "aqui" em dados orais e multimodais, analisamos a ocorrência do dêitico em interações de áudio e em trechos de vídeo, considerando não só o contexto oral, mas também o multimodal, mais especificamente, a unidade gestofala (MCNEILL; CASSELL; LEVY, 1993) nesse último contexto. Os resultados das análises permitiram demonstrar que a conceptualização do dêitico "aqui" depende de diferentes procedimentos linguísticos e cognitivos que refletem o modo pelo qual o individuo interage e interpreta a realidade à sua volta. Enquanto o contexto oral instancia apenas o uso prototípico e o uso do dêitico como marcador discursivo, o contexto multimodal instancia usos metafóricos do dêitico. Sendo assim, "graças ao trabalho criativo do gesto, o espaço não é, de fato, vazio!", já que o gesto encena, metaforicamente, os referentes no espaço. (MCNEILL; CASSEL; LEVY, 1993, p.17). A pesquisa aqui apresentada visa contribuir, a partir de dados empíricos, com os estudos sobre dêixis não apenas do ponto de vista tradicional, relativo à ostensão espacial de instâncias concretas, mas também do ponto de vista cognitivo, que instrumentaliza análises dêiticas do ponto de vista metafórico e discursivo.

\section{Referências}

AVELAR, M.; FERRARI, L. Integração experiencial e dêixis: $O$ papel discursivo dos gestos. Cadernos de Estudos Linguísticos, Campinas, v.59 n.1, p. 73-89, jan./abr. 2017.

BENVENISTE, Emile. $O$ aparelho formal da enunciação. In Problemas de Lingüística Geral II. Campinas: Pontes, 1988.

BENVENISTE, Emile. A natureza dos pronomes. In: Problemas de Lingüística Geral I. São Paulo: Ed. Nacional, Ed. da Universidade de São Paulo, 1976.

CALBRIS, Geneviève. From left to right...: coverbal gestures and their symbolic use of space. In: CIENKI, Alan; MÜLLER, Cornelia. Metaphor and gesture. Amsterdam: John Benjamins, 2008, p. 2754 
CIENKI, Alan Image Schemas and Gestures. In: HAMPE, B; GRADY, J. (Eds.). From Perception to Meaning: Image Schemas in Cognitive Linguistics. Berlin, New York: Mouton de Gruyter, 2005, p. 421-442.

CIENKI, Alan. Frames, Idealized Cognitive Models, and Domains. In: GEERAETS, D.; CUYCKENS, $\mathrm{H}$. (org.) The Oxford Handbook of Cognitive Linguistics. New York: Oxford University Press, 2007, p. 170-187.

FERRARI, L. Introdução à Linguística Cognitiva. São Paulo: Contexto, 2011.

JOHNSON, Mark. The body in the mind: The bodily basis of meaning, imagination, and reason. Chicago, London: The University of Chicago Press, 1987.

JOHNSON, Mark. The meaning of the body: aesthetics of human understanding. Chicago, London: The University of Chicago Press, 2007.

LAKOFF, George. Women, fire, and dangerous things: What categories reveal about the mind. Chicago, London: The University of Chicago Press, 1987.
LAKOFF, George. e JOHNSON, Mark. Metáforas da vida cotidiana. São Paulo: EDUC e Mercado das Letras ,1980.

MARMARIDOU, Sophia. On Deixis. In Pragmatic meaning and cognition. Amsterdam/Philadelphia: John Benjamins, 2000.

MELLO; RASO. (Orgs.). (2012). C-ORAL-BRASIL l: Corpus de referência do português brasileiro falado informal. Belo Horizonte, Editora UFMG.

MCNEILL, D.; CASSELL, J; LEVY, E.T. (1993) Abstract deixis. Semiotica, v. 95, n.1. Berlin: Walter de Gruyter, p. 5-19.

TEIXEIRA, A. C. M.; OLIVEIRA, M. R.;. . Por uma tipologia funcional dos marcadores discursivos com base no esquema construcional Verbo Locativo. Veredas (UFJF. Online), v. 16, p. 19-35, 2012.

YouTube. Felicidade é aqui e agora. Vídeo (16min36s). Disponível em: https://www.youtube.com/watch?v=HsQx02JdZ2Q Acesso em: 10 de março de 2017.

\section{COMO CITAR ESSE ARTIGO}

PASSOS FERRAZ PINHEIRO, Hayat; AVELAR MIRANDA, Maíra. UMA ANÁLISE COGNITIVA DO DÊITICO AQUI EM DADOS ORAIS E MULTIMODAIS. Signo, Santa Cruz do Sul, v. 42, n. 75, dez. 2017. ISSN 19822014. Disponível em: <https://online.unisc.br/seer/index.php/signo/article/view/9815>. Acesso em: . doi: http://dx.doi.org/10.17058/signo.v42i75.9815. 